\title{
ASSESS THE PREVALENCE OF HYPERTENSION AND KNOWLEDGE REGARDING THE PREVENTION OF STROKE
}

\author{
SAHBANATHUL MISSRIYA MA*, JOHNCEY JOHN \\ Department of Physiology, Saveetha College of Nursing, Saveetha University, Chennai, Tamil Nadu, India. Email: contschn002@gmail.com
} Received: 18 March 2017, Revised and Accepted: 29 April 2017

\begin{abstract}
Objective: Hypertension is the most crucial and common health problem in developed and undeveloped countries. Although hypertension is a treatable condition, without treatment, it leads to serious and life-threatening complications such as heart, kidney, and brain disorders. Prevention plays a major role in controlling the disease, which can be achieved by increasing the knowledge through awareness of the public and changing their attitude and practice. The study was aimed to assess the prevalence of hypertension, assess the knowledge regarding prevention of stroke among people with hypertension and to associate the knowledge regarding prevention of stroke with selected demographic variables of people.
\end{abstract}

Methods: Descriptive design was adopted. Using simple random sampling technique, 60 samples were selected. The data were collected, analyzed in terms of both inferential and descriptive statistics.

Results: The study result showed that among the total number of people (1248) surveyed, 476 (38.1\%) were prevalent in hypertension. Among the randomly selected 60 people with hypertension, 47 (78.3\%) patients had inadequate knowledge, 13 (21.7\%) had moderate knowledge, and none of them had adequate knowledge regarding prevention of stroke. Most people residing at Kottayam had poor knowledge on hypertension and prevention of stroke.

Conclusion: The study concluded that though there was more prevalence of hypertension and most of them had inadequate knowledge on prevention of stroke and there is a need to make the people aware about the complications of hypertension and prevention aspects.

Keywords: Assess, Prevalence, Hypertension, Knowledge, Prevention, Stroke.

(C) 2017 The Authors. Published by Innovare Academic Sciences Pvt Ltd. This is an open access article under the CC BY license (http://creativecommons. org/licenses/by/4. 0/) DOI: http://dx.doi.org/10.22159/ajpcr.2017.v10i8.18558

\section{INTRODUCTION}

Hypertension is the silent killer disease, and it has common modifiable risk factor for the development of various diseases. That leads to heart, kidney, and brain disorders, which shows the high prevalence with age in both sexes [1]. Hypertension is one of the crucial problems in developing countries where there is without treatment; it leads to serious and life-threatening conditions [2].

The statistical report estimated that hypertension accounts for 7.5 million deaths, but worldwide, it is about $12.8 \%$ of annual deaths. Around the world, the prevalence of hypertension in person belonging to the age group of 25 years or more is almost $40 \%$, increase of prevalence from 600 million in 1980 to approximately 1 billion in 2008 [3]. It is usually easily treatable disorder, and if untreated, it often leads to complications such as coronary heart disease, stroke, and other vascular complications [4].

A stroke, otherwise known as cerebrovascular accident, is the rapid loss of brain function due to ischemic in the brain caused by blockage or hemorrhage. Due to that, the affected area of the brain loses its function that might result in an inability to move one or more limbs on one side of the body and unable to understand the speech. During a stroke, any lobes can be affected and it may lead to paralysis or imbalance of the body [5]. The death rate attributable to stroke in India is 22 times that of malaria and 1.4 times that of tuberculosis [6].

Stroke symptoms may be sometimes clinically unrecognized among people. The health history of the individual will help to identify the clinical manifestation of stroke. The people in risk to get stroke should aware of the risk factors as well as the important indicators for an enhanced danger of future stroke events [7].
Stroke occurs mainly due to ischemic, causing an acute occlusion of blood flow to the brain because of a thrombus of cerebral origin. Sometimes, it occurs from circulation of another part hemorrhage, caused by a subarachnoid hemorrhage in brain tissues or intracerebral hemorrhage that is between meningeal spaces. Among both, $50-80 \%$ of stroke is contributed by ischemic pathophysiology [8].

People with history should be able to recognize the indications of stroke and this may give a clinically effective and cost economical approach for focusing on prevention of stroke. Early diagnosis and treatment of a stroke usually enhance the patient outcomes. In addition, learning the cause of an initial event is vital for the identification of the appropriate therapy to maximally decrease danger of the disease [9].

Even though many researchers worked on hypertension and stroke-related risk factors, their reporting of its incidence in the Indian population creates a helping tool for better patient care and best medical attention [10].

The objective of this study was to work out the assess the prevalence of hypertension among people, to assess the knowledge regarding the prevention of stroke among people with hypertension, and to associate the knowledge regarding prevention of stroke with selected demographic variables of people.

\section{METHODS}

\section{Research design}

In quantitative research, a descriptive approach under observational method, cross-sectional design was used to assess the prevalence of hypertension and knowledge on prevention of stroke among people with hypertension. The study was conducted in Panachikkadu Grama Panchayat of Kottayam district in Kerala. 


\section{Sampling method}

In this area, more than 10000 people were living in the age group of 40 years and above. Out of them, 1248 people were selected randomly to assess the prevalence of hypertension by survey method. Among them, 476 (38.1\%) were prevalent in hypertension. From them, 60 people were selected using simple random technique (assigned random numbers) to assess the knowledge regarding prevention of stroke. People in the age group of 40 years and above with their willingness included in the study.

\section{Tool}

- Section - A includes demographic variables, which consist of age, sex, religion, educational status, occupation, marital status, duration of hypertension, family history, and type of diet.

- Section - B consists of biological measure, which includes assessment of blood pressure using sphygmomanometer to assess the prevalence of hypertension.

- Section - C consists of structured interview questionnaire method to assess the knowledge regarding prevention of stroke.

The score interpretation for assessing knowledge was $<50 \%$ - inadequate knowledge, $50-75 \%$ - moderate knowledge, and $>75 \%$ - adequate knowledge. The purpose of the study was explained to the people, and their consent was obtained after providing information sheet. The main study was conducted in June-August 2016. The descriptive and inferential statistics were used for data analysis.

\section{RESULTS}

The collected data were analyzed and tabulated for interpreting the results. The study findings showed that the prevalence of hypertension was high. From the 10000 people living at Panachikkadu Grama Panchayat of Kottayam, 1248 people were surveyed for prevalence of hypertension. In that 476 (38.1\%) were in hypertension.

\section{Demographic variables of people with hypertension}

The frequency and percentage distribution of sociodemographic variables of people with hypertension are shown in Table 1. Out of 60 people, $10(16.7 \%)$ participants were in the age group of 40-50 years, $12(20 \%)$ were in the age group of 51-60 years, $14(23.3 \%)$ were in age group of above $61-70$ years, and $24(40 \%)$ were in more than 70 years old. Regarding gender, 27 (45\%) people were male and 33 (55\%) were female. Regarding religion, majority 26 (43\%) were Hindus. About the marital status, $30(50 \%)$ were married. Regarding education in the study group, $10(16.7 \%)$ were illiterate, $20(33.3 \%)$ were studied up to primary education, and $10(16.7 \%)$ were graduated. Regarding the occupation, 10 (16.7\%) people were coolie workers. Regarding income, 29 (48.3\%) were earning less than rupees 3000 per month. Regarding the type of diet, $20(33.3 \%)$ were vegetarian and $20(66.7 \%)$ were non-vegetarian. Regarding the duration of known case of hypertension $21(35 \%)$ for $1-22$ years, 20 (33.3\%) people were having for 2-5 years, $10(16.7 \%)$ were having 5 -10 years and $9(15 \%)$ were known for more than 10 years.

\section{Knowledge level regarding prevention of stroke}

The frequency and percentage distribution of knowledge level regarding the prevention of stroke are shown in Table 2.

Table 2 reveals that out of 60 people with hypertension, 42 (70\%) had inadequate knowledge, 18 (30\%) had moderate knowledge, and none of them had adequate knowledge regarding prevention of stroke.

The mean and standard deviation of the study were 4 and 1.08 .

Association of the knowledge with selected demographic variables Table 3 shows that the association of the knowledge regarding prevention of stroke with selected demographic variables. There was significant association of knowledge with occupation of the people with hypertension.
Table 1: Frequency and percentage distribution of demographic variables of people with hypertension $(n=60)$

\begin{tabular}{|c|c|}
\hline Demographic variables & Frequency (\%) \\
\hline \multicolumn{2}{|l|}{ Age in years } \\
\hline $40-50$ & $10(16.7)$ \\
\hline $51-60$ & $12(20.0)$ \\
\hline $61-70$ & $14(23.3)$ \\
\hline$>70$ & $24(40.0)$ \\
\hline \multicolumn{2}{|l|}{ Gender } \\
\hline Male & $27(45.0)$ \\
\hline Female & $33(55.0)$ \\
\hline \multicolumn{2}{|l|}{ Religion } \\
\hline Hindu & $26(43.3)$ \\
\hline Muslim & $3(05.0)$ \\
\hline Christian & $31(51.7)$ \\
\hline \multicolumn{2}{|l|}{ Education } \\
\hline Illiterate & $10(16.7)$ \\
\hline Primary & $20(33.3)$ \\
\hline Higher secondary & $20(33.3)$ \\
\hline Graduated & $10(16.7)$ \\
\hline \multicolumn{2}{|l|}{ Marital status } \\
\hline Single & $0(0)$ \\
\hline Married & $30(50.0)$ \\
\hline Divorce & $10(16.7)$ \\
\hline Widow & $20(33.3)$ \\
\hline \multicolumn{2}{|l|}{ Occupation } \\
\hline Coolie & $10(16.7)$ \\
\hline Farmer & $11(18.3)$ \\
\hline Employer & $9(15.0)$ \\
\hline Others & $30(50.0)$ \\
\hline \multicolumn{2}{|l|}{ Income per month in rupees } \\
\hline Below-3000 & $29(48.3)$ \\
\hline $3001-5000$ & $11(18.3)$ \\
\hline $5001-10000$ & $10(16.7)$ \\
\hline$>10000$ & $10(16.7)$ \\
\hline \multicolumn{2}{|l|}{ Type of diet } \\
\hline Vegetarian & $20(33.3)$ \\
\hline Non-vegetarian & $40(66.7)$ \\
\hline \multicolumn{2}{|c|}{ Duration known case of hypertension } \\
\hline $1-2$ years & $21(35.0)$ \\
\hline $2-5$ years & $20(33.3)$ \\
\hline $5-10$ years & $10(16.7)$ \\
\hline More than 10 years & $9(15.0)$ \\
\hline
\end{tabular}

F: Frequency; \%: Percentage; $\mathrm{n}=60$

\section{DISCUSSION}

The prevention of stroke is highly important in the promotion of health and to improve the quality of life and reduce the prevalence rate of chronic illness. If the people have adequate knowledge regarding prevention of stroke, that can prevent not only the severity of complications as well as from death. The present study was conducted to assess the prevalence of hypertension and knowledge regarding prevention of stroke.

The first objective was to assess the prevalence of hypertension among people. The present study evidenced that among the 1248 people, 476 (38.1\%) were having hypertension.

Similar study was conducted on factors associated with hypertension prevalence and control among Lebanese people with type 2 diabetes mellitus at a tertiary health-care clinic in Beirut and Mount Lebanon regions. The study resulted that there were 1050 patients received care during the study. Out of which, 715 had type 2 diabetes mellitus. A total of 15 patients were excluded from the study because either they were pregnant (10) or they refused authorization for use of their medical records. The study concluded that out of 700 people with type 2 diabetes mellitus, 529 (75.5\%) were having hypertension and $171(24.5 \%)$ patients were not hypertension [11]. 
Table 2: Frequency distribution of level of the knowledge regarding prevention of stroke $(n=60)$

\begin{tabular}{|c|c|c|c|c|}
\hline \multirow{2}{*}{$\begin{array}{l}\text { Knowledge Level regarding the prevention on } \\
\text { stroke }\end{array}$} & Inadequate knowledge & Moderate knowledge & Adequate knowledge & \multirow[t]{2}{*}{ Mean \pm SD } \\
\hline & No $(\%)$ & No (\%) & No (\%) & \\
\hline & $42(70)$ & $18(30) 0$ & (0) $4 \pm 1.08$ & \\
\hline
\end{tabular}

SD: Standard deviation

Table 3: Association of the knowledge regarding the prevention of stroke with selected demographic variables (n=60)

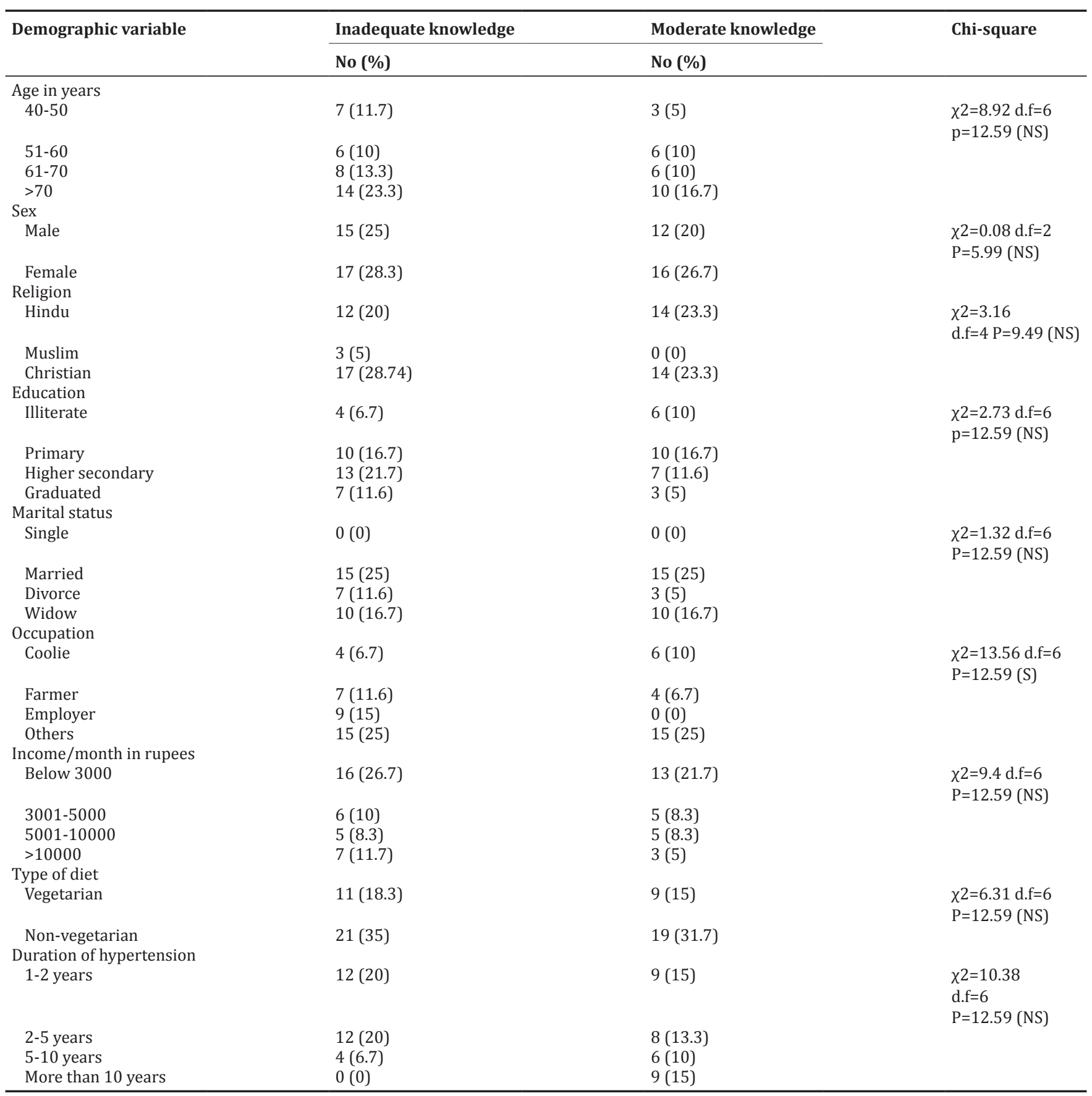

Chi-square; S: Significant NS: Non-significant; d.f: Degrees of freedom

Stroke is a most serious and chronic illness related to atrial fibrillation. Stroke is a main cause of many serious disabilities. The rate of stroke incidences in Indonesia has risen sharply. Indonesia is the only country with the largest number of stroke patients in Asia. India is in the fourth place in the world after China and the United States of America [12].
The study on knowledge of stroke from a sex perspective was conducted in Spain. A representative sample of the population of Extremadura was selected using a double randomization technique. Face-to-face interview was conducted using a structured questionnaire to collect the data. Totally, 2409 participants were interviewed, in which 59.9\% were women. From them, $73 \%$ of all participants reported at least 
one correct warning sign of stroke (OR: 1.01; 95\% CI: 0.84-1.21). The people mentioned as most frequent warning signs were sudden weakness, dizziness, and headache. The study also resulted that women displayed better knowledge of risk factors than men did (OR: 1.23; 95\% CI: 1.05-1.46). Women were more likely to name hypertension as a risk factor for stroke, whereas men more frequently listed smoking, alcohol consumption, and a sedentary lifestyle as risk factors. In response to stroke, women were significantly less likely than men to choose to call an ambulance or to go immediately to hospital [13].

The current study revealed that out of 60 people with hypertension, $42(70 \%)$ had inadequate knowledge, $18(30 \%)$ had moderate knowledge, and none of them had adequate knowledge regarding prevention of stroke. The mean and standard deviation of the study were 4 and 1.08. This result was obtained for the second objective of the study that is to assess the knowledge of stroke among people.

The third objective was to associate knowledge regarding prevention of stroke with selected demographic variables of people. The present study showed that there was no significant association of the knowledge regarding the prevention of stroke with age, sex, religion, education, marital status, income, type of diet, and duration of hypertension and there was significant association with occupation.

The study was conducted to identify about the knowledge of patients regarding stroke and their interpretation of stroke symptoms, and how these factors influence the timing of their decision to seek medical attention. Data were collected and recorded including demographic information, method of transportation, type of stroke symptoms, the patient's interpretation of the symptoms, previous stroke, and knowledge of stroke warning signs. Totally, 67 patients with stroke were interviewed. Approximately, one-fourth of stroke patients correctly interpret their symptoms as representing a stroke. This knowledge is not associated with early presentation to the emergency department [14].

\section{CONCLUSION}

Health-care professionals are known to be the leading source of information and it should utilize the opportunity by educating the public on primary prevention of hypertension and its management. It should be a top priority. This can intend empower the individual as caretakers of their own health. Educating of the population, especially women, will have a great impact on the health of their family members, society. Widespread public education is necessary in the current scenario about the complications of hypertension, the common stroke symptoms, new stroke treatments, and the time constraints of effective therapy to prevent the people from stroke.

\section{REFERENCES}

1. Bennett V. Combating the silent killer that is hypertension. J Nurs Stand 2017;31:28

2. Bushara SO, Noor SK, Ibraheem AA, Elmadhoun WM, Ahmed MH. Prevalence of and risk factors for hypertension among urban communities of North Sudan: Detecting a silent killer. J Fam Med Prim Care 2016;5:605-10.

3. Park K. Hypertension. In: Park's Textbook of Preventive and Social Medicine. $23^{\text {th }}$ ed. Jabalpur, India: Banarsidas Bhanot Publishers; 2015. p. $372-7$.

4. Nayak SR, Jena I, Mishra PK, Behera S, Ray S. Evaluation of serum nitric oxide in essential hypertension and its correlation with severity of disease. Asian J Pharm Clin Res 2016;9:179-82

5. Vurumadla S, Rakshith V, Murari CH, Venkateshwarlu K. A study on symptoms, risk factors and prescribing pattern of drugs used in stroke patients. Int J Pharm Pharm Sci 2015;7:421-6.

6. Banerjee TK, Roy MK, Bhoi KK. Is stroke increasing in India preventive measures that need to be implemented. J Indian Med Assoc 2005;103:162-6.

7. Kleindorfer D, Judd S, Howard V, McClure L, Safford M, Cushman M, et al. Self-reported stroke symptoms without a prior diagnosis of stroke or transient ischemic attack-a powerful new risk factor for stroke. Stroke 2011;42(11):3122-6.

8. Muhit MA. Cardiovascular disease prevalence and prescription patterns at a tertiary hospital in Bangladesh. J Appl Pharmacol Sci 2012;2:80-4.

9. Hart CL, Hole DJ, Smith GD. The relation between questions indicating transient Ischemic attack and stroke in 20 years of follow up in men and women in the Renfrew/paisley study. J Epidemiol Community Health 2001:55:653-6.

10. Spurthi T, Gowthami B, Khyathi D, Vinod G. Risk elements and drug utilization in stroke patients. Int J Pharm Pharm Sci 2016;8:290-2.

11. Soubra L, Nureddin H, Omar AG, Saleh M. Factors associated with hypertension prevalence and control among Lebanese type 2 diabetic patients. Int J Pharm Pharm Sci 2016;8:153-9.

12. Feigin VL, Lawes CM, Bennett DA, Barker-Collo SL, Parag V. Worldwide stroke incidence and early case fatality reported in 56 population-based studies: A systematic review. Lancet Neurol 2009;8(4):355-69.

13. Moreno JM, Alonso-Gonzalez R, Peral-Pacheco P, Millan-Nunez MV, Aguirre-Sánchez JJ. Knowledge of stroke a study from a sex perspective. BMC Res Notes 2015;8:604.

14. Williams LS, Bruno A, Rouch D, Marriott DJ. Stroke patient's knowledge on stroke. Stroke 1997;28:912-5. 